\title{
65 Year Old Patient with Common Variable Immunodeficiency: 3 Years Followup and Development of Lung Adeno Carcinoma, is it a Coincidence?
}

Hasan Yeter $^{1^{\star}}$ and Deniz Cagdas ${ }^{2}$

${ }^{1}$ Department of Internal Medicine, Hacettepe University Medical School, Ankara, Turkey

${ }^{2}$ Department of Pediatric Immunology, Hacettepe University Medical School, Ankara, Turkey

\begin{abstract}
Common variable immunodeficiency(CVID) is a type of primary humoral immunodeficiency which is generally diagnosed at childhood. Recurrent sinopulmonary infections are early presentations of disease. Some of the patients are diagnosed in adulthood. In addition to frequent infections, autoimmune phenomena may occur in about $22 \%$ of patients. Most common autoimmune findings are autoimmune rombocytopenic purpura, hemolytic anemia rheumatoid arthritis and sicca syndrome. Splenomegaly, granulomatous infiltrations, lymphadenopathy may be seen in the course of the disease. Increased risk of malignancies is reported in CVID. Hodgkin lymphoma, most common, intestinal and uterine adeno carcinoma and rarely neuroendocrine tumors are reported with CVID. We report a 65 year-old woman who had diagnosed as rheumatoid artritis, Sjogren syndrome and idiopathic thrombocytopenic purpura. She wasdiagnosed as CVID at the age of 65. After IVIG therapy, rheumatologic diseases had stabile course, but she was diagnosed lung adenocarcinoma 3 year after her diagnosis.
\end{abstract}

\section{Introduction}

Common variable immunodeficiency (CVID) is a type of immunodeficiency characterized by reduced serum immunglobulin (Ig)G, IgA with or without $\operatorname{IgM}$ and reduced or absent specific antibody response [1-3]. CVID is the most frequent human primary immunodeficiency and prevalence of CVID is 1:25000 [2]. Some of patients are diagnosed in childhood but generally they are diagnosed after puberty typically at the ages between 20-40 [3]. Due to the heterogenous nature of the disease, 6 or 7 years delay in diagnosis is common [4].

CVID patients have an increased risk not only to infectious diseases, but also autoimmune diseases, granulomatous diseases, gastrointestinal inflammatory diseases, malabsorption and malignancy. The association of noninfectious complications were given as follows; autoimmunity, 25-31\%; chronic lung disease, 28.5\%; bronchiectasis, $11.2-24 \%$; gastrointestinal inflammatory disease, 14-15.4\%; malabsorption, 5-5.9\%; granulomatous disease, 8-9.7\%; lymphoma, 5-10\%; and other cancers, $5.8-7 \%$ [3-5]. In the literature neoplasms in CVID patients are most commonly lymphomas and gastric carcinomas [6]. In a cohort of 476 subjects with CVID,six breast, three colon, three gastric, two mouth, two melanoma, one lung, one skin, one ovary and one vaginal carcinoma have been reported [4]. Gastrointestinal stromal tumor and adenosquamous carcinoma of sigmoid colon have also been reported [7].

Herein, we report a female patient who had been diagnosed with CVID at 65 years old. She developed lung adenocarcinoma three years after CVID diagnosis. Lung adenocarcinoma has never been reported as a case in conjunction with CVID.

\section{Case Report}

A 65 year-old woman admitted to hospital with arthritis. She had been diagnosed as rheumatoid artritis, Sjogren syndrome and idiopathic thrombocytopenic purpura before. She had history of 30 years cigarette use and left smoking for 5 years. Her physical examination was normal except swelling of the right elbow and wrist. Joints were painful and swollen. Despite azathioprine and deltacortril therapy, her disease was not under control.

She had recurrent pneumonia history at her childhood. At the age of 23 years, she has arthritis, and diagnosed as acute rheumatic fever. At 29 years old, she was diagnosed as idiopathic thrombocytopenic purpura when she admitted with purpura. Bone marrow findings were found to be normal. At 63 years of age, she admitted to hospital again with the symptoms of arthritis and dry mouth. She was diagnosed as rheumatoid arthritis and Sjogren syndrome. In the childhood, she had recurrent pyelonephritis (Table 1), but no urinary system anomaly was recorded. At her administration to our hospital, biochemical analysis was normal except increased liver function tests (Table 2). Hepatosteatosis was detected at her hepatobiliary ultrasonography. Her viral hepatitis markers and thyroid functions tests were normal. Her autoimmune markers were all normal. Abdominal CT was normal except hepatosteatosis. Patient's serum IgG and IgA levels were decreased, anti A-B titres were 1/128-1/64. Flow cytometry showed; within normal range of CD3, CD4, CD8, CD16-56 and CD19. She was investigated for co-morbidities and complications of CVID, there is no spesific finding observed at pulmonary computerized tomography (CT). She was diagnosed as CVID and IvIG treatment was started 400 $\mathrm{mg} / \mathrm{kg}$ monthly.

At her 3 years follow up, her disease was under control her liver function test were normalized and serum IgG levels were held within normal range (Table 3). Arthritis did not recurred, and no severe infection was observed. She was consulted to chest disease department with the symptoms of cough and chest pain developed for a month. Pulmonary parenchymal mass was detected at thoracal CT (Figure 1). Endobronchial biopsy was performed and pathologic evalation revealed adenocarcinoma of lung. After diagnosis Cisplatin chemotherapy regimen was started. Altough 3 Cisplatin regimen her disease was progressive. Now Taxotere and Carboplatin regimen is started

\section{Discussion}

${ }^{*}$ Corresponding author: Hasan Yeter, Department of Internal Medicine, Hacettepe University Medical School, Ankara, Turkey, Tel: 05542397449; E-mail: hasanyeter@hotmail.com

Received May 01, 2015; Accepted July 23, 2015; Published July 27, 2015

Citation: Yeter H, Cagdas D (2015) 65 Year Old Patient with Common Variable Immunodeficiency: 3 Years Followup and Development of Lung Adeno Carcinoma, is it a Coincidence?. J Pulm Respir Med 5: 277. doi:10.4172/2161-105X.1000277

Copyright: ( 2015 Yeter $\mathrm{H}$, et al. This is an open-access article distributed under the terms of the Creative Commons Attribution License, which permits unrestricted use, distribution, and reproduction in any medium, provided the original author and source are credited. 
Citation: Yeter H, Cagdas D (2015) 65 Year Old Patient with Common Variable Immunodeficiency: 3 Years Followup and Development of Lung Adeno Carcinoma, is it a Coincidence?. J Pulm Respir Med 5: 277. doi:10.4172/2161-105X.1000277

Page 2 of 3

\begin{tabular}{|c|c|}
\hline Infectious complications & Non-infectious complications \\
\hline Recurrent penumonia & Acute rheumatic fever \\
\hline Recurrent pyelonephritis & Idiopathic thrombocytopenic purpura \\
\hline & Thyroiditis \\
\hline & Dermatomyositis \\
\hline & Rheumatoid artritis \\
\hline
\end{tabular}

Table 1: Complications of CVID in our patient.

\begin{tabular}{|c|c|c|c|c|c|}
\hline & Result & Normal Range & & Result & Normal Range \\
\hline $\mathrm{ALT}^{*}$ & $476 \mathrm{u} / \mathrm{L}$ & $<33$ & ANA $^{*}$ & Negative & \\
\hline $\mathrm{AST}^{*}$ & $207 \mathrm{u} / \mathrm{L}$ & $<31$ & ENA- SsA & Negative & \\
\hline $\mathrm{GGT}^{*}$ & $1190 \mathrm{u} / \mathrm{L}$ & $<36$ & ENA-SsB & Negative & \\
\hline $\mathrm{ALP}^{*}$ & $218 \mathrm{u} / \mathrm{L}$ & $<104$ & ENA-Jo1 & Negative & \\
\hline T.Bilirubin & $0.4 \mathrm{mg} / \mathrm{dl}$ & $0.1-1.2$ & ENA-Scl70 & Negative & \\
\hline Albumin & $4 \mathrm{~g} / \mathrm{dl}$ & $3.4-4.8$ & Anti Phospholipid IgM & Negative & \\
\hline Creatinin & $0.82 \mathrm{mg} / \mathrm{dl}$ & $0.5-0.9$ & Anti Phospholipid IgG & Negative & \\
\hline $\mathrm{CK}^{*}$ & $141 \mathrm{u} / \mathrm{L}$ & $26-192$ & Anti TPO* & Negative & \\
\hline $\mathrm{LDH}^{*}$ & $923 \mathrm{u} / \mathrm{L}$ & $240-480$ & Anti $\mathrm{HBc}$ total & Negative & \\
\hline $\mathrm{TSH}^{*}$ & $1.7 \mathrm{ulU} / \mathrm{L}$ & $0.27-4.2$ & Anti HBs & $14 \mathrm{n} \mathrm{lu} / \mathrm{ml}$ & $0-10$ \\
\hline Hemoglobin & $13.4 \mathrm{~g} / \mathrm{dl}$ & $11.7-15.5$ & Anti HCV & Negavtive & \\
\hline $\mathrm{MCV}^{*}$ & $89.7 \mathrm{fl}$ & $80-95$ & $\mathrm{C} 3^{*}$ & $128 \mathrm{mg} / \mathrm{dl}$ & $79-152$ \\
\hline Leukocyte & $11 \times 10^{3} \mu \mathrm{L}$ & $4-11.2 \times 10^{3}$ & $\mathrm{C} 4^{*}$ & 25 mg/dl & $16-38$ \\
\hline Neutrophil & $9.9 \times 10^{3} \mu \mathrm{L}$ & $1.8-6.4 \times 10^{3}$ & CD3 & $55 \%$ & $54-84$ \\
\hline Thrombocyte & $318 \times 10^{3} \mu \mathrm{L}$ & $159-388 \times 10^{3}$ & CD4 & $41 \%$ & $32-62$ \\
\hline Sedimentation & $17 \mathrm{~mm} / \mathrm{h}$ & $0-25$ & CD16-56 & $30 \%$ & $5-39$ \\
\hline C-rp* & $2.46 \mathrm{mg} / \mathrm{dl}$ & $0-0.8$ & CD19 & $6 \%$ & $4-19$ \\
\hline $\mathrm{RF}^{*}$ & Negative & & $\mathrm{CH} 50$ & $14 \mathrm{u} / \mathrm{ml}$ & $>15$ \\
\hline
\end{tabular}

ALT: Alanine Transaminase; AST: Aspartate Aminotransferase; GGT: Gamma-Glutamyl Transferase; ALP: Alkaline Phosphatase; CK: Creatine Kinase; LDH: Lactate Dehydrogenase; TSH: Thyroid Stimulating Hormone; MCV: Mean Corpuscular Volume; CRP: C-Reactive Protein; RF: Rhematoid Factor; ANA: Anti Nuclear Anticor; TPO: Thyroperoxidase Antibody; C3:Complement 3; C4:Complement 4.

Table 2: Laboratory tests.

\begin{tabular}{|c|c|c|c|c|c|c|}
\hline & $03 / 2013$ & $06 / 2013$ & $05 / 2014$ & $11 / 2014$ & $02 / 2015$ & Normal Range \\
\hline $\lg G$ & 423 & 600 & 837 & 813 & 867 & $751-1560 \mathrm{mg} / \mathrm{dl}$ \\
\hline $\lg A$ & 58 & 63 & 82 & 76 & 90 & $82-453 \mathrm{mg} / \mathrm{dl}$ \\
\hline $\lg M$ & 125 & 169 & 268 & 252 & 390 & $46-304 \mathrm{mg} / \mathrm{dl}$ \\
\hline
\end{tabular}

Table 3: Serum Ig Levels within years.
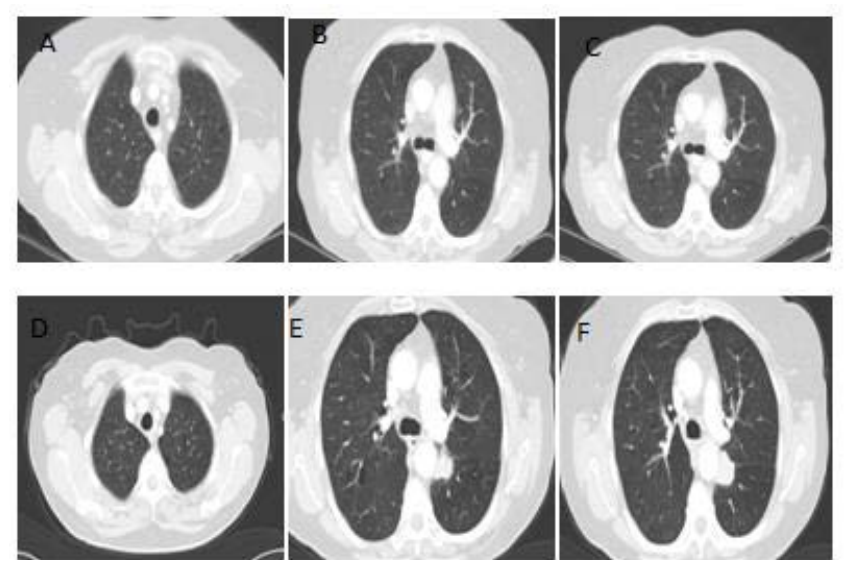

Figure 1: (A-C) During the evaluation of complications of CVID. (D-F) 3 years after diagnosis, left inferior-superior lobe $28 \times 23 \mathrm{~mm}$ nodule.

Although some of patients are diagnosed in childhood, generally CVID is diagnosed after puberty within ages between 20-40 (3).There was a mean diagnostic delay of 7.46 years (range $0-61$ year old) in a
European cohort study [8] and 8.9 years in an Italian cohort [9]. The life expectancy of CVID patients has improved over the past 30 years and the average life expectancy is 50 years [10]. CVID was diagnosed at the age of 65 in our case. Although her infectious symptoms occured at childhood and autoimmune phenomena such as arthritis and thrombocytopenia occured at adulthood, the diagnosis delayed for many years.

Most common cause of mortality in CVID is malignancy, especially lymphomas. The overall survival of patients have improved over time [3]. However malignity risk is increased in CVID due to the association with chronic infections, immunodeficiency and autoimmune conditions, well known risk factors for lymphomas and solid neoplasms [11]. Lymphomas is also associated with other immunodeficiency syndromes but lung adenocarcinoma is not a well known complication neither CVID nor the others. The overall risk of gastric carcinoma and non-Hodgkin lymphoma is increased 7-16 and 12-18 times higher respectively in CVID [12]. Mechanism of gastric cancer in CVID patients is relevant to reduced secretory IgA and achlorhydria. At the end of this process $H$. pylori infection and chronic inflammation risk rises and contribute gastric cancer [13]. On the other hand, multiple solid tumors such as colorectal adenocarcinoma, basal cell carcinoma and uterine adenocarcinoma are rarely reported in the 
Citation: Yeter H, Cagdas D (2015) 65 Year Old Patient with Common Variable Immunodeficiency: 3 Years Followup and Development of Lung Adeno Carcinoma, is it a Coincidence?. J Pulm Respir Med 5: 277. doi:10.4172/2161-105X.1000277

literature [2]. Small numbers of solid tumors associate makes it difficult to ascertain if these are increased in CVID [11] is the most common cause of lung carcinoma, but $25 \%$ are not associated with cigarette use [14]. Outdoor air pollution, cooking oil fumes, coal fumes, asbestosis, obesity, lack of physical activity and heavy alcohol consumption also rise lung carcinoma risk.To the best of our knowledge, this is the first reported case of lung adenocarcinoma with CVID but in our opinion datas association with this two rare condition are not sufficient. Because she had 30 years smoking history and hard to say direct association lung adenocarcinoma with CVID. Further research is needed on this issue.

\section{References}

1. Jolles $S$ (2013) The variable in common variable immunodeficiency: a disease of complex phenotypes. J Allergy Clin Immunol Pract 1: 545-556.

2. Todorovic M, Balint B, Andjelic B, Mihaljevic B (2014) Multiple malignancies in a female patient with common variable immunodeficiency syndrome. Singapore Med J 55: e162-164.

3. Resnick ES, Moshier EL, Godbold JH, Cunningham-Rundles C (2012) Morbidity and mortality in common variable immune deficiency over 4 decades. Blood 119: 1650-1657.

4. Cunningham-Rundles C1 (2010) How I treat common variable immune deficiency. Blood 116: 7-15.

5. Fernández Romero DS, Juri MC, Paolini MV, Malbrán A (2013) [Common variable immunodeficiency. Epidemiology and clinical manifestations in 69 patients]. Medicina (B Aires) 73: 315-323.

6. Gottesman SR, Haas D, Ladanyi M, Amorosi EL (1999) Peripheral T cell lymphoma in a patient with common variable immunodeficiency disease: case report and literature review. Leuk Lymphoma 32: 589-595.

7. Watkins C, Sahni R, Holla N, Litchfield J, Youngberg G, et al. (2012) Malignancy in common variable immune deficiency: report of two rare cases of gastrointestinal malignancy and a review of the literature. Cardiovasc Hematol Disord Drug Targets 12: 21-27.

8. Chapel H, Lucas M, Lee M, Bjorkander J, Webster D, et al. (2008) Common variable immunodeficiency disorders: division into distinct clinical phenotypes. Blood 112: 277-286.

9. Quinti I, Soresina A, Spadaro G, Martino S, Donnanno S, et al. (2007) Longterm follow-up and outcome of a large cohort of patients with common variable immunodeficiency. J Clin Immunol 27: 308-316.

10. Lin LJ, Wang YC, Liu XM1 (2015) Clinical and immunological features of common variable immunodeficiency in China. Chin Med J (Engl) 128: 310-315.

11. Notarangelo LD (2010) Primary immunodeficiencies. J Allergy Clin Immuno 125: S182-194.

12. Cunningham-Rundles $C$, Bodian $C$ (1999) Common variable immunodeficiency: clinical and immunological features of 248 patients. Clin Immunol 92: 34-48.

13. Gangemi S, Allegra A, Musolino C (2015) Lymphoproliferative disease and cancer among patients with common variable immunodeficiency. Leuk Res 39: 389-396.

14. Okazaki I, Ishikawa S, Sohara Y (2014) Genes associated with succeptibility to lung adenocarcinoma among never smokers suggest the mechanism of disease. Anticancer Res 34: 5229-5240. 